\title{
Desempenho Escolar da Criança Vitimizada encaminhada ao Fórum Judicial ${ }^{1}$
}

\author{
Paulo Celso Pereira ${ }^{2}$ \\ Universidade Federal de São Carlos \\ Adriana Barbosa dos Santos \\ Universidade Estadual Paulista, São José do Rio Preto \\ Lúcia Cavalcanti de Albuquerque Williams \\ Universidade Federal de São Carlos
}

\begin{abstract}
RESUMO - O objetivo do estudo foi caracterizar o desempenho escolar da criança vítima de violência doméstica atendida no Fórum Judicial. Participaram do estudo 20 crianças vitimizadas comparadas com seus pares da mesma sala de aula, mesmo sexo e mesma faixa etária, mas sem histórico de violência doméstica, suas respectivas mães e professoras. As crianças responderam ao Teste de Desempenho Escolar, Inventário de Estilos Parentais e ao Teste de Raven (Escala Especial) e apresentaram o caderno escolar. As mães responderam a uma entrevista e a Escala de Táticas de Conflitos Revisada (CTS-2). As professoras apresentaram sua opinião sobre o desempenho acadêmico dos participantes. Os dados obtidos mostraram que a criança vitimizada tem desempenho escolar inferior ao grupo controle. Os resultados da CTS-2 indicaram que a maioria das crianças vitimizadas estava exposta à violência conjugal. O estudo mostrou que, além da violência doméstica direta e indireta, tais crianças estavam expostas a outros fatores de risco, tais como, pobreza, baixa escolaridade materna e uso de álcool e/ou droga por familiares.
\end{abstract}

Palavras-chave: violência doméstica; desempenho escolar; criança vitimizada; educação inclusiva.

\section{School Performance of Victimized Children seen by the Judiciary System}

\begin{abstract}
The aim of this study was to characterize the school performance of victimized children assisted by the Judicial System. Twenty victimized children's school performances were compared to their peers of the same classroom, gender, age, but without a history of family violence. Their respective mothers and teachers also took part in this study. Children from both groups answered The Academic Performance Test, Parenting Styles Inventory and the Raven's Progressive Matrices Test. The children also gave samples of their notebook production. Children's mothers answered a family interview and the Revised Conflict Tactics Scales (CTS-2). Teachers offered their impressions on student's academic performance. Results indicated inferior academic performance by the victimized child, when compared with their matched group. According to teachers, victimized children had inferior academic performance in relation to their non-victim peers. CTS- 2 results indicated that most of victimized children were exposed to marital violence. Moreover, the study shows that, besides direct and indirect domestic violence, these children were exposed to other risk factors, such as, poverty, maternal low educational level and alcohol/drugs used by relatives.
\end{abstract}

Keywords: domestic violence; school performance; victimized children; inclusive education.

A violência que ocorre no ambiente familiar recebe a denominação de violência intrafamiliar ou doméstica ${ }^{3}$. Tal fenômeno tem como vítimas preferenciais os idosos, os incapacitados, as crianças e a mulher. Essa violência pode causar ferimentos ou a morte da vítima. A violência doméstica não distingue classe social, etnia, credo religioso etc. (Saffioti, 1997).

1 Parte deste trabalho foi derivada da dissertação de Mestrado do primeiro autor.

2 Endereço: Rua Marília 505, Bairro São Francisco. Catanduva, SP. CEP 15806-315. Fones: (17) 35222830 ou (17) 9776 5058. E-mail: paulocelsop@ig.com.br.

3 Neste trabalho a expressão'violência doméstica' é empregada como sinônimo de violência intrafamiliar, entendida como a violência que ocorre no contexto familiar, seja contra a mulher ou contra a criança. Em inglês, a expressão domestic violence quer dizer agressão à mulher.
Para proteger, assegurar e defender os direitos da criança e do adolescente, o Brasil tem uma das leis mais avançadas do mundo, trata-se do Estatuto da Criança e do Adolescente (ECA) - Lei Federal no 8.069, de 13/07/90 (Brasil, 1990). O ECA consagra para a infância e juventude os direitos fundamentais prescritos no artigo 227 da Constituição Federal de 1988 (Moraes, 2004).

Ainda para a proteção da criança e do adolescente, foram criados, na década de 80, o Centro Regional de Atenção aos Maus-Tratos na Infância (CRAMI) e a Associação Brasileira Multiprofissional de Proteção à Infância e à Adolescência (ABRAPIA). Em defesa da mulher agredida, foram criadas, também na década de 80 , as Delegacias de Defesa da Mulher (DDM). O ordenamento jurídico brasileiro, embora timidamente, vem ampliando os direitos da mulher, a exemplo do novo Código Civil (Brasil, 2002) e da Lei N ${ }^{o} 11.106$, de 28/03/05 (Brasil, 2005). 
Mesmo com os serviços existentes e com o amparo da legislação, estima-se que a violência doméstica marque a sua presença em nossa sociedade, atingindo um grande número de famílias. Os dados nacionais sobre o fenômeno em discussão são escassos e, geralmente, são relativos a amostras muito específicas (Brino, 2002).

A violência doméstica ocorre por meio de uma das seguintes modalidades: física, psicológica, sexual e negligência (Azevedo \& Guerra, 1989). Quanto à criança, esta pode ser atingida pela violência doméstica de duas maneiras: direta e indireta. Se alvo do abuso, a criança é considerada vítima direta. Se exposta às cenas de agressão entre os pais (violência conjugal), será tida como vítima indireta (Brancalhone \& Williams, 2003).

A literatura indica que a criança vitimizada tem o desenvolvimento prejudicado. Os efeitos nocivos da exposição (direta e/ou indireta) à violência intrafamiliar podem ser observados no funcionamento cognitivo e emocional e na vida escolar e social (Wolfe, Crooks, Lee, McIntyre-Smith \& Jaffe, 2003). Assim, a violência doméstica deixa sequelas na saúde mental da criança. Os sintomas citados com mais frequência na literatura são: falta de motivação, isolamento, ansiedade, comportamento agressivo, depressão e baixo desempenho escolar (Brancalhone, Fogo \& Williams, 2004). Com relação ao declínio do desempenho escolar da criança vitimizada, falase em: dificuldade de aprendizagem, pouco aproveitamento, falta de motivação, evasão escolar, repetência e necessidade de educação especial (Brancalhone \& cols., 2004).

A revisão da literatura dos últimos 10 anos sobre violência doméstica revela a existência de muitas publicações no Brasil e no exterior. No entanto, quando se busca a associação desse tema com desempenho escolar, o volume de pesquisa se restringe. Nos Estados Unidos da América, Veltman e Browne (2001) realizaram uma análise dos estudos sobre violência doméstica produzidos nas últimas três décadas e constataram que a maioria deles mostrou que a criança vitimizada tinha atraso cognitivo e na área de linguagem. Os autores constataram, ainda, que em $91 \%$ dos estudos as crianças que sofriam violência em casa tinham baixo desempenho escolar e, frequentemente, estudavam em classe especial. Para Veltman e Browne (2001), a violência doméstica é um tema complexo pelo fato de a criança raramente ser vítima de uma única modalidade de abuso, bem como por estar associada, geralmente, a problemas sócio-econômicos.

Leiter e Johnsen (1997) realizaram, também, nos EUA, um estudo longitudinal, no qual associaram baixo desempenho escolar com negligência e maus tratos na infância. Os resultados mostraram que os maus tratos têm uma correlação estatisticamente significativa com o declínio no desempenho acadêmico, correlação essa que pode variar com a intensidade e severidade da violência doméstica.

Quanto à literatura nacional, o estudo conduzido por Brancalhone e cols. (2004) avaliou o desempenho escolar de 15 crianças expostas à violência conjugal (Grupo A), pareando-as com crianças da mesma sala de aula, mesmo sexo e mesma faixa etária, mas não expostas à violência conjugal (Grupo B). Foram coletados dados com as mães e com as professoras. As mães responderam a uma entrevista e a Escala de Táticas de Conflito Revisada - CTS-2 (Straus, Hamby, Boney-McCoy \& Sugarman, 1996), enquanto as professoras ofereceram o Boletim Escolar dos participantes e preencheram a Escala de Avaliação da Performance Acadêmica - EAPA (DuPaul, Rapport \& Perriello, 1991). Com as crianças, foi utilizado o Teste de Desempenho Escolar - TDE (Stein, 1994). Com exceção dos resultados da EAPA, o estudo não revelou diferenças estatisticamente significativas entre os dois grupos nos demais dados obtidos (TDE, Boletim Escolar e avaliação das mães sobre o desempenho escolar de seus filhos). Segundo Brancalhone e cols. (2004), é possível que as diferenças encontradas na EAPA tenham ocorrido porque as professoras tinham conhecimento prévio de quem havia ou não sido exposto à violência conugal, sendo influenciadas por esse conhecimento ao avaliar tais crianças. Adicionalmente, os autores comentam que, considerando a literatura atual, não é prudente relacionar qualquer impacto da violência sobre o desempenho escolar (ver também Wolfe \& cols., 2003).

A associação entre desempenho escolar e violência doméstica é um importante tema de pesquisa, pois tais aspectos representam questões essenciais na vida de muitas crianças, interessando, assim, aos profissionais não só da Educação e da Educação Especial, como da Psicologia Escolar, Psicologia do Desenvolvimento e Psicologia Jurídica, enfim, para todos que procuram respostas para o atendimento adequado às vítimas da violência que ocorre no interior dos lares.

No estudo de Brancalhone e cols. (2004) participaram, exclusivamente, crianças expostas à violência conjugal (vítimas indiretas de violência doméstica). Assim, face ao número alarmante de vítimas de violência doméstica, é preciso conduzir mais pesquisas que mostrem os reflexos de tal fenômeno no rendimento escolar de crianças vitimizadas de maneira direta e/ou indireta (Assis, 2002). Assim, o objetivo do presente estudo foi o de caracterizar o desempenho escolar da criança encaminhada ao Fórum Judicial na condição de vítima de violência doméstica, seja de maneira direta (alvo do abuso) e/ou indireta (exposição à agressão conjugal).

\section{Método}

\section{Participantes}

Participaram deste estudo 40 crianças de ambos os sexos, que foram divididas em dois grupos, de acordo com os seguintes critérios:

Grupo A (GA). Vinte crianças com idade entre 7 e 10 anos, de ambos os sexos, estudantes de uma das séries do primeiro ciclo do Ensino Fundamental, que residiam com as suas famílias. Essas crianças foram encaminhadas ao Setor Técnico de Psicologia do Fórum da cidade de CatanduvaSP, o qual atende outros Fóruns da região, por serem vítimas diretas e/ou indiretas de violência doméstica.

Grupo B (GB). Cada criança do GA foi pareada com uma do GB, sendo estas da mesma sala de aula, do mesmo sexo, da mesma faixa etária e vivendo com a família, mas sem relato de violência doméstica. Ou seja, tais crianças não sofriam violência em casa, condição que foi pesquisada na escola, com a mãe e com a própria criança.

As 40 mães e 18 professoras das crianças selecionadas para compor o GA e o GB também participaram da pesquisa. 


\section{Local, materiais e instrumentos}

A coleta de dados com as crianças e com as professoras realizou-se nas escolas. Com as mães, a coleta de dados ocorreu em suas respectivas residências.

Para a coleta de dados foram utilizados os seguintes instrumentos e materiais:

\section{- Instrumentos utilizados com as crianças}

a) Teste de Desempenho Escolar - TDE (Stein, 1994). Desenvolvido no Brasil, esse teste permite a avaliação objetiva das capacidades fundamentais para o desempenho escolar. O teste é composto por três subtestes: Escrita (escrita do próprio nome e de palavras isoladas sob a forma de ditado), Aritmética (solução oral de problemas e cálculo de operações aritméticas por escrito) e Leitura (reconhecimento de palavras isoladas do contexto).

b) Inventário de Estilos Parentais - IEP (Gomide, 2003). Essa escala, desenvolvida no Brasil, contém 42 itens correspondentes a sete práticas educativas. $\mathrm{O}$ instrumento tem duas formas, uma que é respondida pelos pais e a outra em que são os filhos que respondem. Nessa pesquisa foi empregada essa segunda forma, nas suas duas versões: Práticas Parentais Paternas e Práticas Parentais Maternas.

c) Matrizes Progressivas Coloridas de Raven - Escala Especial. É um teste de inteligência não verbal desenvolvido na Grã-Bretanha por J.C. Raven em 1947 (Raven, 1957). Esse instrumento avalia os processos intelectuais de crianças na faixa etária de 5 a 11 anos, de deficientes mentais e de pessoas idosas. Está dividido em três séries: A, AB e B, cada uma delas com 12 problemas, os quais estão impressos com fundo colorido. O teste foi aplicado seguindo as normas do manual de Angelini, Alves, Custódio, Duarte e Duarte (1999).

d) Boletim Escolar. Esse documento escolar foi solicitado às professoras para registrar o conceito das crianças nas disciplinas de Português e de Matemática.

e) Caderno Escolar. A fotocópia de seis páginas do caderno escolar das crianças permitiu analisar seu nível de elaboração da escrita. Para a referida análise foi criado um protocolo de registro, baseando-se nas definições de Marturano (1999).

\section{Instrumentos utilizados com as mães:}

a) Entrevista Semi-Estruturada. Roteiro de entrevista elaborado para se obter dados como: composição e renda familiar, profissão e escolaridade dos pais etc.

b) Escala de Táticas de Conflito Revisada - CTS-2 (Revised Conflict Tactics Scale-CTS-2, Straus \& cols., 1996). É uma escala composta por 78 itens, cada um deles contendo uma afirmação que permite constatar as seguintes modalidades de violência conjugal: física, psicológica e sexual. Os autores dividiram o instrumento em cinco subescalas: negociação, violência psicológica, violência física, coerção sexual e ferimentos. Utilizou-se a tradução de Cortez e Williams (2002), autorizada pelos autores.

Instrumento utilizado com as professoras:

a) Entrevista Semi-Estruturada. Esse material foi elaborado com o propósito de conhecer a opinião das professoras sobre o desempenho escolar dos participantes.

\section{Procedimento}

Para a triagem dos participantes do GA, o primeiro autor consultou o arquivo do Setor Técnico de Psicologia do Fórum da Comarca de Catanduva-SP e selecionou 20 crianças atendidas nesse setor em razão de ação judicial, na qual figuravam como vítimas de violência doméstica. Para compor o GB foi solicitada à direção das escolas frequentadas pelos participantes do GA a indicação de crianças da mesma sala de aula, mesmo sexo e idade aproximada, mas sem histórico conhecido de violência em casa.

As mães de ambos os grupos foram convidadas a participar da pesquisa, bem como a autorizar a participação do filho e, ao concordarem, assinavam o Termo de Consentimento Livre e Esclarecido. As professoras das crianças participantes também eram esclarecidas sobre o projeto e, caso aceitassem participar do mesmo, assinavam o referido termo. Todas as mães do GB concordaram em participar, bem como todas as professoras consultadas. Uma mãe convidada para compor o GA não aceitou, e uma diretora de escola particular, na qual estudava uma criança vitimizada, não permitiu a coleta de dados na escola.

O primeiro autor coletou dados com as crianças e com as professoras na escola. Com as crianças foram realizadas duas sessões; com as professoras, além da entrevista, foi solicitado o caderno de atividade escolar dos participantes, bem como o Boletim Escolar destes, para o registro dos conceitos em Português e Matemática. A coleta de dados com as mães foi conduzida em suas casas, em uma sessão, na qual preencheram a CTS-2 e responderam à entrevista. $\mathrm{O}$ projeto foi aprovado pelo Comitê de Ética em Pesquisa da Universidade Federal de São Carlos (UFSCar).

Os dados sócio-demográficos, os escores do Teste de Raven e os resultados do TDE foram analisados estatisticamente pelo teste $t$ de Student. A análise estatística das respostas ao Inventário de Estilos Parentais realizou-se pelo Teste de Fisher.

\section{Resultados}

As crianças participantes estavam cursando uma das quatro primeiras séries do Ensino Fundamental, sendo que: seis cursavam a $1^{\mathrm{a}}$ série; 10 a $2^{\mathrm{a}}$ série; 10 a $3^{\mathrm{a}}$ série e 14 , a $4^{\mathrm{a}}$ série. Em relação ao gênero, 20 eram do sexo masculino e 20 do sexo feminino. A idade mínima foi de 7 anos e 2 meses e a idade máxima de 10 anos e 11 meses. A Tabela 1 ilustra tais características.

Conforme mostrado na Tabela 2, a comparação entre os grupos (A e B) quanto aos dados demográficos, por meio do teste $t$ de Student, não indicou evidências de diferenças significativas $(p>0,05)$ para as variáveis renda familiar e renda $p e r$ capita. Já para a variável escolaridade da mãe, verificou-se uma diferença estatisticamente significativa $(p=0,03)$. No $\mathrm{GB}$, a pontuação média com relação à escolaridade da mãe foi 3,82 anos, quase o dobro da pontuação média do GA, como ilustrado na Tabela 2.

Além dos dados demográficos, a entrevista com as mães permitiu conhecer as seguintes características familiares: estado civil - no GA predominou a união estável e no GB 
Tabela 1. Idade e série cursada pelas crianças participantes: grupos A e B.

\begin{tabular}{|c|c|c|c|c|c|c|c|}
\hline \multicolumn{4}{|c|}{ Grupo A } & \multicolumn{4}{|c|}{ Grupo B } \\
\hline Participante & Sexo & Idade & Série & Participante & Sexo & Idade & Série \\
\hline 1 & $\mathrm{~F}$ & $8 \mathrm{a}, 1 \mathrm{~m}$ & $2^{\mathrm{a}}$ & 1 & $\mathrm{~F}$ & $8 \mathrm{a}, 4 \mathrm{~m}$ & $2^{\mathrm{a}}$ \\
\hline 2 & $\mathrm{~F}$ & $10 \mathrm{a}, 8 \mathrm{~m}$ & $4^{\mathrm{a}}$ & 2 & $\mathrm{~F}$ & $10 \mathrm{a}, 3 \mathrm{~m}$ & $4^{\mathrm{a}}$ \\
\hline 3 & $\mathrm{~F}$ & $9 \mathrm{a}, 5 \mathrm{~m}$ & $2^{\mathrm{a}}$ & 3 & $\mathrm{~F}$ & $9 \mathrm{a}, 0 \mathrm{~m}$ & $2^{\mathrm{a}}$ \\
\hline 4 & M & $10 \mathrm{a}, 3 \mathrm{~m}$ & $4^{\mathrm{a}}$ & 4 & M & $10 \mathrm{a}, 0 \mathrm{~m}$ & $4^{\mathrm{a}}$ \\
\hline 5 & M & $8 \mathrm{a}, 9 \mathrm{~m}$ & $3^{\mathrm{a}}$ & 5 & M & $9 \mathrm{a}, 5 \mathrm{~m}$ & $3^{\mathrm{a}}$ \\
\hline 6 & M & $8 \mathrm{a}, 11 \mathrm{~m}$ & $2^{\mathrm{a}}$ & 6 & M & $8 \mathrm{a}, 5 \mathrm{~m}$ & $2^{\mathrm{a}}$ \\
\hline 7 & $\mathrm{~F}$ & $10 \mathrm{a}, 0 \mathrm{~m}$ & $3^{\mathrm{a}}$ & 7 & $\mathrm{~F}$ & $9 \mathrm{a}, 8 \mathrm{~m}$ & $3^{\mathrm{a}}$ \\
\hline 8 & $\mathrm{~F}$ & $10 \mathrm{a}, 3 \mathrm{~m}$ & $4^{\mathrm{a}}$ & 8 & $\mathrm{~F}$ & $10 \mathrm{a}, 6 \mathrm{~m}$ & $4^{\mathrm{a}}$ \\
\hline 9 & $\mathrm{~F}$ & $7 \mathrm{a}, 3 \mathrm{~m}$ & $1^{\mathrm{a}}$ & 9 & $\mathrm{~F}$ & $7 \mathrm{a}, 4 \mathrm{~m}$ & $1^{\mathrm{a}}$ \\
\hline 10 & M & $7 \mathrm{a}, 8 \mathrm{~m}$ & $1^{\mathrm{a}}$ & 10 & M & $7 \mathrm{a}, 2 \mathrm{~m}$ & $1^{\mathrm{a}}$ \\
\hline 11 & M & $10 \mathrm{a}, 5 \mathrm{~m}$ & $4^{\mathrm{a}}$ & 11 & M & $9 \mathrm{a}, 10 \mathrm{~m}$ & $4^{a}$ \\
\hline 12 & $\mathrm{~F}$ & $8 \mathrm{a}, 1 \mathrm{~m}$ & $2^{\mathrm{a}}$ & 12 & $\mathrm{~F}$ & $8 \mathrm{a}, 0 \mathrm{~m}$ & $2^{\mathrm{a}}$ \\
\hline 13 & M & $9 a, 6 m$ & $3^{\mathrm{a}}$ & 13 & M & $9 \mathrm{a}, 5 \mathrm{~m}$ & $3^{\mathrm{a}}$ \\
\hline 14 & $\mathrm{~F}$ & $9 \mathrm{a}, 5 \mathrm{~m}$ & $3^{\mathrm{a}}$ & 14 & $\mathrm{~F}$ & $9 \mathrm{a}, 7 \mathrm{~m}$ & $3^{\mathrm{a}}$ \\
\hline 15 & $\mathrm{~F}$ & $10 \mathrm{a}, 11 \mathrm{~m}$ & $4^{\mathrm{a}}$ & 15 & $\mathrm{~F}$ & $10 \mathrm{a}, 10 \mathrm{~m}$ & $4^{\mathrm{a}}$ \\
\hline 16 & M & $9 \mathrm{a}, 1 \mathrm{~m}$ & $2^{\mathrm{a}}$ & 16 & M & $8 \mathrm{a}, 10 \mathrm{~m}$ & $2^{\mathrm{a}}$ \\
\hline 17 & M & $10 \mathrm{a}, 7 \mathrm{~m}$ & $4^{\mathrm{a}}$ & 17 & M & $10 \mathrm{a}, 5 \mathrm{~m}$ & $4^{\mathrm{a}}$ \\
\hline 18 & $\mathrm{~F}$ & $8 \mathrm{a}, 11 \mathrm{~m}$ & $3^{\mathrm{a}}$ & 18 & $\mathrm{~F}$ & $9 \mathrm{a}, 1 \mathrm{~m}$ & $3^{\mathrm{a}}$ \\
\hline 19 & M & $7 \mathrm{a}, 7 \mathrm{~m}$ & $1^{\mathrm{a}}$ & 19 & M & $7 \mathrm{a}, 8 \mathrm{~m}$ & $1^{\mathrm{a}}$ \\
\hline 20 & M & $10 \mathrm{a}, 9 \mathrm{~m}$ & $4^{\mathrm{a}}$ & 20 & M & $10 \mathrm{a}, 11 \mathrm{~m}$ & $4^{\mathrm{a}}$ \\
\hline
\end{tabular}

Tabela 2. Comparação de dados demográficos das famílias dos grupos A e B.

\begin{tabular}{|c|c|c|c|c|c|c|c|}
\hline Variáveis & Grupo & $\mathbf{N}$ & Média (desvio) & Mínimo & Máximo & Estatística $t$ & $p$ \\
\hline & $\mathrm{A}$ & 20 & $2,59(0,30)$ & 0 & 5,48 & & \\
\hline \multirow[t]{3}{*}{ Renda familiar } & & & & & & $-1,63$ & 0,110 \\
\hline & $\mathrm{B}$ & 20 & $3,29(0,31)$ & 1,44 & 7,69 & & \\
\hline & A & 19 & $0,58(0,09)$ & 0 & 1,37 & & \\
\hline \multirow[t]{3}{*}{ Renda per capita } & & & & & & $-1,85$ & 0,072 \\
\hline & $\mathrm{B}$ & 20 & $0,79(0,07)$ & 0,28 & 1,54 & & \\
\hline & A & 20 & $2,95(2,42)$ & 0 & 7 & & \\
\hline \multirow[t]{2}{*}{ Escolaridade (Mãe) } & & & & & & $-2,27$ & $0,030^{*}$ \\
\hline & B & 20 & $5,25(3,82)$ & 0 & 11 & & \\
\hline
\end{tabular}

Nota: Renda familiar e per capita em salário mínimo; escolaridade em anos; *diferença significativa ao nível de 0,05. 
a grande maioria das mães $(80 \%)$ eram casadas; número de filhos - as mães do GA possuíam, em média, o dobro de filhos que as mães do GB, respectivamente, quatro e dois filhos; moradia - quatro famílias do GA, contra 14 do GB, habitavam casa com um cômodo ou mais por morador; profissão - 55\% das mães do GA e 70\% das mães do GB eram donas-de-casa, enquanto os pais de ambos os grupos, na sua grande maioria, exerciam trabalho manual, que não exigia qualificação profissional; religião - o GA dividiu-se em $40 \%$ de católicos, $30 \%$ de protestantes e $30 \%$ sem credo religioso; o GB dividiu-se em $60 \%$ de católicos, $35 \%$ de protestantes e $5 \%$ sem religião; uso de álcool/droga - no GB não existia o consumo de álcool e/ou droga, de acordo com as informações das mães; no GA, a grande maioria (75\%) das mães relatou um histórico de envolvimento com álcool e/ou droga.

Quanto aos indicadores de violência doméstica, variável presente somente no GA, os dados obtidos indicaram que as crianças desse grupo, além de vítimas diretas, na sua grande maioria (85\%) também eram vítimas indiretas, pois estavam expostas à violência conjugal.

Enquanto vítimas diretas, os agressores eram: pai/mãe (35\%), padrasto (20\%), mãe (15\%), pai ( $15 \%$ ), pai/mãe/padrasto $(5 \%)$, tio materno $(5 \%)$ e um amigo que sempre conviveu com a família (5\%). O período de vitimização oscilou de 4 meses a 7 anos, sendo a média de 3 anos. A co-morbidade (mais de uma modalidade de abuso ao mesmo tempo) foi verificada em $50 \%$ das crianças; $20 \%$ eram vítimas de negligência; $15 \%$ de abuso físico; $10 \%$ sofreram abuso sexual e $5 \%$, abuso psicológico. De acordo com o relato da mãe de 11 crianças do GA, além do filho participante, um outro era vítima direta de violência doméstica, do mesmo agressor.

Sobre a violência conjugal, apenas três mães do GA negaram a existência de agressão entre o casal. Das 17 que admitiram essa ocorrência, uma alegou que era ela quem agredia seu parceiro; nos demais casos $(94,12 \%)$, as mulheres afirmaram serem vítimas. O período de violência entre o casal oscilou de 1 ano a 32 anos. Em 75\% dos casos, a criança já estava exposta à violência conjugal (vítima indireta), antes de se tornar alvo direto da violência doméstica.

Os resultados obtidos com a CTS-2 confirmaram as informações das mães do GA quanto à existência da violência conjugal. A aplicação desse material às mães do GB indicou a ausência de violência entre o casal, condição para compor esse grupo. As Figuras 1 (GA) e 2 (GB) mostram as modalidades de violência conjugal de acordo com a CTS-2. Segundo os dados oferecidos pelas mães, a média da agressão sofrida por elas foi de $34,71 \%$ para o GA e $1 \%$ para o GB. A média da violência contra os pais do GA e do GB foi, respectivamente, $11,57 \%$ e $1,12 \%$.

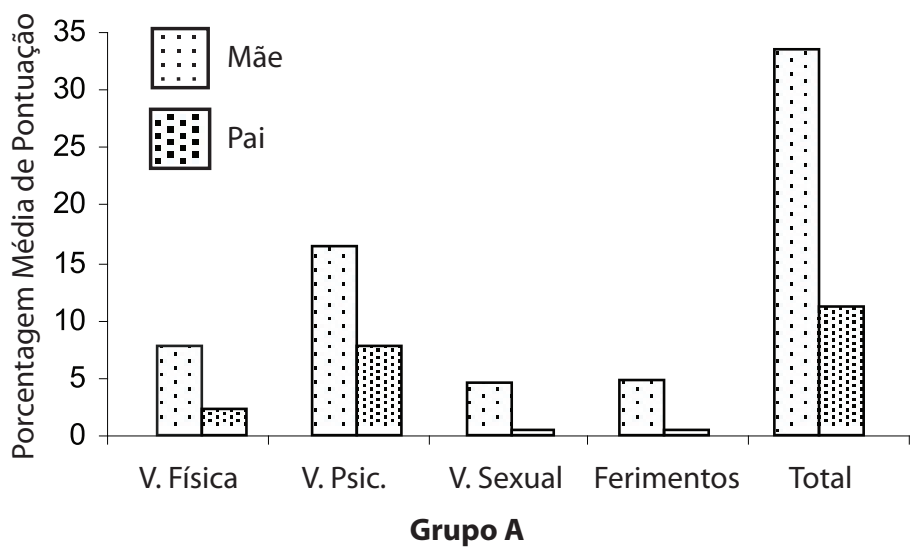

Figura 1. Porcentagem média da pontuação de violência conjugal apresentada na CTS-2 para o Grupo A (V=violência, Psic=psicológica)

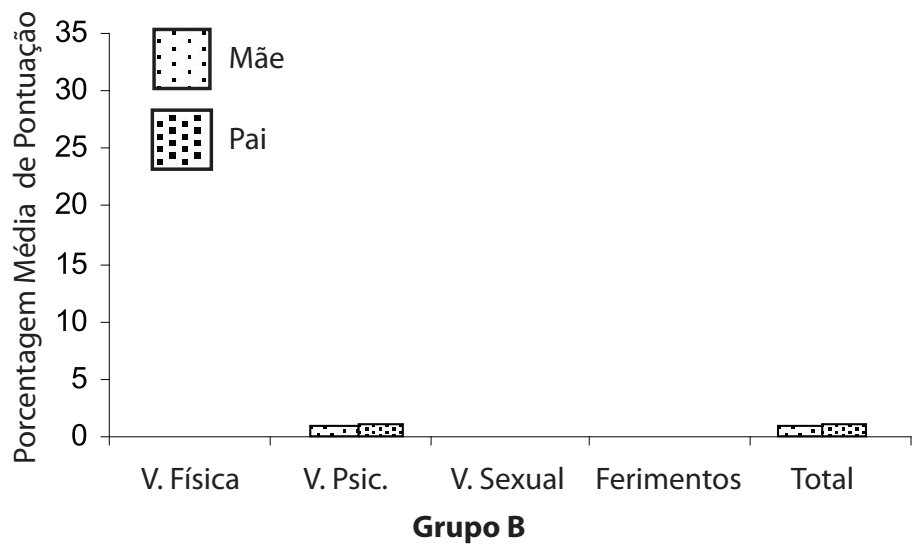

Figura 2. Porcentagem média da pontuação de violência conjugal apresentada na CTS-2 para o Grupo B (V=violência, Psic=psicológica). 
A Tabela 3 mostra os resultados obtidos no IEP (práticas parentais paternas e práticas parentais maternas). A análise estatística, com base no Teste de Fisher, revelou uma diferença significativa entre GA e GB quando ao uso do estilo parental de risco, sendo essa prática parental verificada, de acordo com as respostas das crianças, em $65 \%$ dos pais do GA, contra 5\% do GB $(p=0,0001)$. Dados semelhantes foram encontrados para as mães: $75 \%$ das mães do Grupo A apresentavam práticas de risco, enquanto apenas $15 \%$ do Grupo B faziam o mesmo $(p=0,0003)$.

No Teste de Raven (Escala Especial), 75\% das crianças do GA e 70\% das crianças do GB apresentaram capacidade intelectual na média. Nenhum participante do GB teve resultado abaixo da média; no GA, 15\% revelaram capacidade intelectual abaixo da média. Alguns participantes apresentaram capacidade intelectual acima da média: $10 \%$ das crianças do GA e 30\% do GB. Para a análise comparativa entre os grupos quanto aos percentis obtidos pelos participantes no Teste de Raven, foram efetuados cálculos estatísticos com o teste $t$ de Student. Tal análise não revelou diferença estatisticamente significativa entre GA e GB ( $p=0,997)$, como mostra a Tabela 4.

Com relação aos indicadores do desempenho escolar, na entrevista, as mães expressaram suas opiniões quanto ao rendimento escolar do filho, classificando-o em: ótimo, bom, regular, ruim, e péssimo. A mesma pergunta foi feita para as professoras. Na maioria, as mães do GA atribuíram notas mais positivas aos seus filhos do que as professoras, sendo que o percentual da discordância entre elas foi de 60 . No
GB, o percentual de discordância entre mães e professoras foi de 55, portanto, menor em relação ao GA. Esse resultado demonstra, quanto ao GB, não apenas mais concordância entre mães e professoras, como um melhor desempenho das crianças na visão das professoras.

O Boletim Escolar mostrou que, tanto em Português, como em Matemática, as crianças do GB possuíam melhor conceito do que as do GA. Em ambas as disciplinas, a maioria das crianças do GB tinha conceito plenamente satisfatório enquanto o conceito da maioria das crianças do GA foi satisfatório.

A Tabela 5 contém os resultados da análise estatística, pelo teste $t$ de Student, dos dados obtidos com o TDE. Verifica-se que os grupos apresentam uma diferença significativa no subteste de Escrita $(p=0,020)$ e no Escore Bruto Total $(p=0,03)$. Com relação aos subtestes de Aritmética e Leitura, o desempenho das crianças do GA foi inferior ao das crianças do GB, mas tais diferenças não foram estatisticamente significativas $(p>0,05)$.

Por meio do caderno de atividade escolar foi analisado o nível de elaboração da escrita. Os dados obtidos mostraram que $45 \%$ das crianças do GA se encontravam no nível escreve palavras e texto (sem organização); 40\%, no nível escreve palavras e texto (com organização); 15\%, no nível com intenção de escrita; e 5\%, no nível escrevia palavras (sem fazer texto). No GB, 90\% das crianças escreviam palavra e texto (com organização) e $10 \%$ escreviam palavras (sem fazer texto).

Tabela 3. Distribuição de freqüências do IEP - Práticas Parentais Paternas e Maternas: grupos A e B.

\begin{tabular}{|c|c|c|c|c|}
\hline \multirow{2}{*}{ Práticas Parentais } & & \multicolumn{2}{|c|}{ Grupos } & \multirow{2}{*}{$p$} \\
\hline & & $\mathbf{A}$ & B & \\
\hline \multicolumn{5}{|l|}{ Paternas } \\
\hline Risco & $\mathrm{F}(\%)$ & $13(65 \%)$ & $1(5 \%)$ & $0,0001^{*}$ \\
\hline Sem Risco $^{1}$ & F (\%) & $7(35 \%)$ & $19(95 \%)$ & \\
\hline \multicolumn{5}{|l|}{ Maternas } \\
\hline Risco & $\mathrm{F}(\%)$ & $15(75 \%)$ & $3(15 \%)$ & $0,0003^{*}$ \\
\hline Sem Risco $^{1}$ & $\mathrm{~F}(\%)$ & $5(25 \%)$ & $17(85 \%)$ & \\
\hline
\end{tabular}

Nota: ${ }^{1}$ Estilo parental ótimo e estilo parental bom (acima/abaixo da média); *diferença significativa ao nível de 0,05 encontrada apenas nas famílias com estilo parental de risco.

Tabela 4. Resultados estatísticos dos percentis do Teste de Raven: grupos A e B.

\begin{tabular}{|c|c|c|c|c|c|c|c|}
\hline Variável & Grupo & $\mathbf{N}$ & $\begin{array}{l}\text { Média } \\
\text { (desvio) }\end{array}$ & Mínimo & Máximo & Estatística $t$ & $p$ \\
\hline \multirow{2}{*}{ Percentis } & $\mathrm{A}$ & 20 & $\begin{array}{c}46,0 \\
(18,3)\end{array}$ & 10,0 & 80,0 & \multirow{2}{*}{$-2,57$} & \multirow{2}{*}{0,997} \\
\hline & B & 20 & $\begin{array}{c}63,5 \\
(18,9)\end{array}$ & 30,0 & 99,0 & & \\
\hline
\end{tabular}


Tabela 5. Resultados obtidos com o Teste de Desempenho Escolar-TDE: grupos A e B.

\begin{tabular}{|c|c|c|c|c|c|c|c|}
\hline TDE & Grupo & $\mathbf{N}$ & Média (desvio) & Mínimo & Máximo & Estatística $t$ & $p$ \\
\hline \multirow[b]{2}{*}{ Escrita } & A & 20 & $17,5(8,73)$ & 1 & 28 & \multirow[b]{2}{*}{$-2,42$} & \multirow[b]{2}{*}{$0,020^{*}$} \\
\hline & $\mathrm{B}$ & 20 & $23,6(7,13)$ & 2 & 32 & & \\
\hline \multirow{2}{*}{ Aritmética } & $\mathrm{A}$ & 20 & $11,30(5,89)$ & 2 & 20 & \multirow{2}{*}{$-1,87$} & \multirow{2}{*}{0,070} \\
\hline & B & 20 & $11,30(5,64)$ & 3 & 21 & & \\
\hline \multirow{2}{*}{ Leitura } & A & 17 & $57,8(10,1)$ & $0(29)^{* *}$ & 70 & \multirow{2}{*}{$-1,39$} & \multirow{2}{*}{0,138} \\
\hline & $\mathrm{B}$ & 18 & $61,7(5,6)$ & $7(47)^{* *}$ & 70 & & \\
\hline \multirow{2}{*}{ EBT } & A & 18 & $86,6(25,7)$ & $5(15)^{* *}$ & 114 & \multirow{2}{*}{$-2,30$} & \multirow{2}{*}{$0,03 *$} \\
\hline & B & 20 & $102(12,7)$ & $11(77)^{* *}$ & 123 & & \\
\hline
\end{tabular}

Nota: EBT = Escore Bruto Total; *diferenças significativas ao nível de 0,$05 ; * *$ valores identificados como outliers estão fora do parêntesis e não são incluídos no resultado do teste.

\section{Discussão}

Este estudo mostrou que a criança vítima de violência em casa, encaminhada ao Fórum Judicial, tem o desempenho escolar inferior a seus pares, da mesma sala de aula, mesmo sexo e mesma faixa etária, mas sem histórico de violência doméstica. Por outro lado, o presente trabalho não encontrou diferença significativa entre GA e GB quanto à capacidade intelectual.

O presente estudo mostrou ainda que, atrelados à violência doméstica, existem outros fatores de risco, tais como: pobreza (sendo esta constatada em ambos os grupos), família numerosa, práticas parentais de risco, presença de álcool e/ ou droga e baixa escolaridade materna. Segundo Barnett (1997) e Veltman e Browne (2001), a violência intrafamiliar, geralmente, está associada a outras condições adversas, que comprometem o rendimento escolar e a cognição.

Quanto à violência doméstica, fator de risco presente apenas no GA, os dados revelaram que, na grande maioria dos casos, além de sofrerem diretamente mais de uma modalidade de abuso ao mesmo tempo, a chamada co-morbidade (Azevedo \& Guerra, 1989; Brino, 2002), as crianças estavam expostas às cenas de agressão entre o casal, portanto, também eram vítimas indiretas de violência intrafamiliar. $\mathrm{O}$ estudo revelou que, em 55\% dos casos, outra(s) criança(s) da família, além da participante do estudo, era(m) vítima(s) direta(s), ou seja, alvo da agressão.

Em relação à violência conjugal, os dados da CTS-2 revelaram que a vítima era, na grande maioria, a mãe da criança. Embora a agressão entre o casal fosse presumida, os resultados obtidos foram alarmantes, pois em alguns casos, a violência conjugal foi mais frequente e intensa do que a denunciada contra a criança.

Os grupos A e B apresentaram restrições financeiras que permitem dizer que as famílias viviam na pobreza. A análise estatística das variáveis renda familiar e renda per capita não revelaram diferenças significativas entre os grupos. A ocupação dos pais e as residências pequenas para o número de moradores, tanto para o GA, como para o GB, reforçaram a condição de pobreza das famílias.

Os grupos A e B residiam em casas pequenas para a quantidade de moradores, por cômodo, situação essa mais evidente no GA, o que pode ser explicado não apenas pelas condições físicas do imóvel, mas pelo tamanho da família, pois as mães do GA tinham o dobro de filhos do que as mães do GB. Cabe lembrar que habitar casa pequena para o número de moradores é uma ameaça ao bem-estar da família e, portanto, uma condição adversa para o desenvolvimento (Gallo \& Williams, 2008; Veltman \& Browne, 2001).

Um outro fator de risco presente nas famílias do GA foi a falta de habilidade dos pais na educação e cuidados com os filhos (Barnett, 1997), pois quando as crianças preencheram o Inventário de Estilos Parentais (IEP), predominou o estilo parental de risco tanto para os pais, como para as mães do GA. Os resultados obtidos com o IEP revelaram que as crianças vítimas de violência doméstica tinham pais negligentes e que faziam uso das práticas educativas punitivas, tal como apontado pela literatura existente sobre esse tema (Barnett, 1997; Veltman \& Browne, 2001). Para Gomide (2003), nas famílias de baixo poder aquisitivo, a monitoria dos pais em relação aos filhos pode ficar prejudicada, resultando em práticas parentais negativas. Para Guille (2004), o consumo abusivo de álcool e/ou droga interfere nas habilidades parentais. Ainda segundo esse autor, o uso de álcool e/ou droga é um importante fator de risco a ser considerado na etiologia e tratamento do homem que agride seu filho.

De acordo com Veltman e Browne (2001), o uso de álcool é um fator de risco comumente associado à violência doméstica. Os dados do presente estudo apoiam tal argumentação, uma vez que $75 \%$ das mães do GA afirmaram que sua família tinha um histórico marcado pelo consumo de álcool e/ou droga, sendo que a maioria delas atribuiu essa prática ao parceiro. Com relação ao GB, segundo o relato das mães, não existia uso de álcool e/ou droga por qualquer um dos membros da família. 
Com relação à escolaridade materna, já está demonstrado (Stevenson \& Baker, 1987) que as mães com mais escolaridade têm um maior envolvimento nas atividades escolares do filho, o que pode resultar num melhor desempenho escolar deste. Assim, a participação dos pais, em especial, da mãe na vida escolar do seu filho parece ser um preditor significativo do processo acadêmico, da infância até a juventude (D'AvilaBacarji, Marturano \& Elias, 2005). No presente estudo, as mães do GB possuíam mais anos de escolaridade do que as mães do GA, diferença essa estatisticamente significativa. No entanto, em ambos os grupos havia mães com menos de quatro anos de estudo, o que se constitui, de acordo com a literatura, um fator de risco para o desempenho escolar de seus filhos. No GB, as crianças expostas à baixa escolaridade materna tiveram no Teste de Desempenho Escolar (TDE) melhores resultados do que as crianças do GA, também expostas a esse fator de risco. Portanto, considerando os dados do TDE, pode-se supor que a violência doméstica (direta e indireta) e a co-ocorrência de outras variáveis que sugerem tratar-se de um lar hostil (falta de habilidades parentais e o uso de álcool e/ou droga), prevaleceram sobre a baixa escolaridade materna.

As mães de ambos os grupos avaliaram mais positivamente os filhos do que as professoras. Estas, por sua vez, consideraram o rendimento escolar do GA inferior ao do GB. Embora as educadoras soubessem quais eram as crianças vitimizadas, deram um conceito mais negativo (regular, ruim e péssimo) para as que viviam em contexto familiar com um maior número de fatores de risco, sugerindo certa coerência nas suas avaliações e que tinham conhecimento das dificuldades acadêmicas das crianças do GA. Na entrevista, ao apresentarem sua opinião sobre as crianças do Grupo $\mathrm{A}$, as professoras disseram que estas eram indisciplinadas, agressivas, apáticas e desatentas.

Os conceitos do Boletim Escolar em Português e Matemática das crianças do GA, na sua maioria, foram satisfatórios. No GB, para ambas as disciplinas, o conceito que predominou foi o plenamente satisfatório. Embora com uma concentração de conceitos dentro da média, por parte do GA, os conceitos do GB foram melhores.

A tendência a um rendimento escolar mais prejudicado para as crianças do GA, quando comparadas com os participantes do GB também foi verificada nos resultados do TDE. A mediana dos escores das crianças do GA foi inferior ao das crianças do GB, nos três subtestes e no Escore Bruto Total (EBT), sendo que para o subteste de Escrita e no EBT, essa diferença foi estatisticamente significativa.

Brancalhone e cols. (2004) também usaram o TDE e não constataram diferenças estatisticamente significativas nos resultados obtidos pelo grupo exposto à violência conjugal e pelo grupo não exposto, lembrando que aquele estava exposto à violência entre o casal, mas não era alvo direto da agressão. No presente estudo, além de vítima direta de violência doméstica, os dados revelaram que as crianças sofriam mais de um tipo de agressão ao mesmo tempo e estavam expostas à violência conjugal. Para explicar a diferença nos resultados do TDE entre tais estudos, pode-se levantar duas hipóteses: (1) a violência doméstica direta tem efeitos mais danosos para o desempenho escolar da criança do que a indireta. Segundo Wolfe e cols. (2003), apesar de existir argumentação teórica para dizer que a exposição à violência conjugal tenha impacto na aprendizagem, a literatura quanto a esse assunto ainda é escassa, não havendo estudos suficientes sobre a referida associação; (2) a soma de vários fatores de risco pode prejudicar mais o desenvolvimento da criança do que um fator de risco isoladamente (Sameroff, Seifer, Baldwin \& Baldwin, 1993).

Com relação à avaliação do nível de elaboração da escrita das crianças (GA e GB), os resultados obtidos confirmaram os dados do TDE e dos demais indicadores de desempenho escolar analisados, ou seja, uma melhor competência das crianças do GB, em relação às do GA, para escrever palavras e textos. Portanto, um pior desempenho para as crianças do GA no subteste de Escrita do TDE foi corroborado pela análise do nível de elaboração da escrita. Os resultados do Teste de Raven (Escala Especial) foram equivalentes para os grupos A e B, o que reforça a hipótese de que as dificuldades encontradas no TDE, bem como em outros indicadores de desempenho escolar do GA, a priori, não podem ser atribuídas a um déficit na esfera cognitiva.

Considerando que o desenvolvimento cognitivo das crianças do GA não estava comprometido, e que os dados do TDE nos subtestes de Aritmética e Leitura não revelaram diferenças significativas entre estas e as crianças do GB, pode-se levantar a hipótese de que, mesmo sob condições de risco, as crianças vitimizadas apresentavam indícios de resiliência, ou seja, formas positivas de responder ao estresse e à adversidade (Williams \& Aiello, 2004).

Apesar dos fatores de risco, $70 \%$ das mães do GA alegaram que a família tinha religião. No GB, $95 \%$ das famílias tinham credo religioso. Portanto, o contexto familiar marcado pela violência doméstica pode apresentar recursos facilitadores da resiliência, como a religião (Werner, 1998). No GA, apenas uma criança não participava do culto religioso adotado por sua família.

Este estudo revelou que a maioria das crianças vítimas diretas de violência no lar estava exposta à violência conjugal, sendo a mulher, em tal modalidade de agressão, a vítima preferencial. A co-ocorrência de violência doméstica direta e indireta já foi apontada na literatura internacional (O'Leary, Slep \& O'Leary, 2000), mas, até esse momento, a referida co-ocorrência não havia sido mostrada na literatura brasileira.

\section{Considerações Finais}

Este trabalho permitiu caracterizar o desempenho escolar da criança vitimizada (GA), bem como traçar um perfil do seu contexto familiar, comparando-a com a criança não vitimizada (GB). Os resultados obtidos mostraram que a violência intrafamiliar é um fenômeno complexo, pois a grande maioria das crianças do GA sofria mais de uma modalidade de abuso (co-morbidade) e estava exposta à violência conjugal, sendo a sua mãe a vítima preferencial desta modalidade de agressão. $\mathrm{O}$ estudo revelou, ainda, que a violência doméstica está associada a outros fatores de risco, a saber: pobreza (presente em ambos os grupos), baixa escolaridade materna, pais que usam estilo parental de risco e presença de álcool e/ou droga. Essas duas primeiras condições podem limitar o 
acesso a recursos facilitadores do desenvolvimento da criança (Ferreira \& Marturano, 2002).

Considerando que as crianças do GA tinham passado por atendimento junto ao Setor Técnico de Psicologia do Fórum da Comarca de Catanduva-SP, fica a sugestão aos assistentes sociais e psicólogos judiciários para que, ao atenderem a criança vítima de violência em casa, tenham o foco na família como um todo, pois este estudo mostrou que a violência doméstica está associada a outras condições adversas e, mais, que é comum que a mãe dessa criança seja agredida pelo parceiro. Assim, tais profissionais precisam estar atentos a essa realidade, visando garantir os direitos da mulher. Para Sinclair (1985), o fim da agressão contra a mulher é uma forma de combater a violência contra a criança, pois a segurança da mãe se reverte, mesmo que indiretamente, na segurança do filho.

O presente estudo abordou os fatores de risco existentes no ambiente familiar marcado pela violência doméstica, mas deixou de contemplar os fatores de proteção, ou seja, recursos e competências que podem estar presentes no referido contexto, seja no indivíduo ou na família. Portanto, é preciso desenvolver mais estudos que associem violência doméstica e desempenho escolar. Para tanto, e visando compreender fenômeno tão complexo, seria importante realizar estudos longitudinais.

\section{Referências}

Angelini, A. L., Alves, I. C. B., Custódio, E. M., Duarte, W. F., \& Duarte, J. L. M. (1999). Matrizes Progressivas Coloridas de Raven: escala especial. São Paulo: Centro Editorial de Testes e Pesquisas em Psicologia.

Assis, S. G. (2002). Crescendo em meio à violência. Em M. F. Westphal (Org.), Violência e criança (pp. 115-124). São Paulo: EDUSP.

Azevedo, M. A., \& Guerra, V. N. A. (1989). Crianças vitimizadas: a síndrome do pequeno poder. São Paulo: Iglu.

Barnett, D. (1997). The effects of early intervention on maltreating parents and their children. Em M. J. Guralnick (Org.), The effectiveness of early intervention. (pp. 147-170). Baltimore: Paul H. Brookes.

Brancalhone, P. G., \& Williams, L. C. A. (2003). Crianças expostas à violência conjugal: uma revisão de área. Em M. A. Almeida, M. C. Marquezine \& E. D. O. Tanaka (Orgs.), O papel da família junto ao portador de necessidades especiais. Pers-pectivas multidisciplinares em Educação Especial (pp. 123-130). Londrina: Eduel.

Brancalhone, P. G., Fogo, J. C., \& Williams, L. C. A. (2004). Crianças expostas à violência conjugal: avaliação do desempenho acadêmico. Psicologia: Teoria e Pesquisa, 20, 113-117.

Brasil (1990). Estatuto da Criança e do Adolescente. Juiz de Fora: Universidade Federal de Juiz de Fora.

Brasil (2002). Código Cível (Lei $N^{o} 10.406$, de 10/01/2002) (54 ${ }^{\mathrm{a}}$ ed.) São Paulo: Saraiva.

Brasil (2005). Lei $N^{o} 11.106$, de 28/03/2005 - altera os arts. 148, 215, 216, 226, 227, 231 e acrescenta o art. 231-A ao DecretoLei $n^{\circ}$. 2.848, de 07/12/1940 - Código Penal e das outras providências. Brasília: Diário Oficial da União.
Brino, R. F. (2002). Capacitação do educador acerca do abuso sexual infantil. Dissertação de Mestrado, Universidade Federal de São Carlos, São Carlos.

Cortez, M. B., \& Williams, L. C. A. (2002). Grupo terapêutico cognitivo comportamental com homens que agridem fisicamente suas parceiras. Monografia de Curso de Graduação em Psicologia, Universidade Federal de São Carlos, São Carlos.

D’Avila-Bacarji, K. M. G., Marturano, E. M., \& Elias, L. C. S. (2005). Recursos e adversidades no ambiente familiar de crianças com desempenho escolar pobre. Cadernos de Psicologia e Educação (Padéia), 15, 43-55.

DuPauL, G. J., Rapport, M. D., \& Perriello, L. M. (1991). Teacher ratings of academic skills: The development of the Academic Rating Scale. Psychology Review, 20, 284-300.

Ferreira, M. C. T., \& Marturano, E. M. (2002). Ambiente familiar e os problemas do comportamento apresentados por crianças com baixo desempenho escolar. Psicologia: Reflexão e Crítica, $15,35-44$.

Gallo, A. E., \& Williams, L. C. A. (2008). A escola como fator de proteção à conduta infracional de adolescentes. Cadernos de Pesquisa, 38, 41-59.

Gomide, P. I. C. (2003). Estilos parentais e comportamento antisocial. Em A. Del Prette \& Z. Del Prette (Orgs), Habilidades sociais, desenvolvimento e aprendizagem (pp. 21-60). Campinas: Alínea.

Guille, L. (2004). Men who batter and their children: An integrated review. Aggression and Violent Behavior, 9, 129-163.

Leiter, J., \& Johnsen, M. C. (1997). Child maltreatment and school performance declines: An event-history analysis. American Educational Research Journal, 34, 563-589.

Marturano, E. M. (1999). Recursos no ambiente familiar e dificuldades de aprendizagem na escola. Psicologia: Teoria e Pesquisa, 15, 135-142.

Moraes, A. (2004). Direito Constitucional (16 a ed.). São Paulo: Atlas.

O’Leary, K. D., Slep, A. M. S., \& O'Leary, S. G. (2000). Cooccurrence of partner and parent aggression: Research and treatment implications. Behavior Therapy, 31, 631-648.

Raven, J. C. (1957). Test de Matrices Progresivas. Escala Especial. Manual (4a ed.). Buenos Aires: Paidós.

Saffioti, H. I. B. (1997). Violência doméstica ou a lógica do galinheiro. Em M. Kupstas (Org.), Violência em debate (pp. 39-57). São Paulo: Moderna.

Sameroff, A. J., Seifer, R., Baldwin, A., \& Baldwin, C. (1993). Stability of intelligence from preschool to adolescence: The influence of social and family risk factors. Child Development, 64, 80-97.

Sinclair, D. (1985). Understanding wife assault: A training manual for counselors and advocates. Toronto: Publications Ontario.

Stein, L. M. (1994). TDE - Teste de desempenho escolar: manual para aplicação e interpretação. São Paulo: Casa do Psicólogo.

Stevenson, D. J. \& Baker, D. P. (1987). The family-school relation and the child's school performance. Child Development, 58, 1348-1357.

Straus, M. A., Hamby, S. H., Boney-McCoy, S., \& Sugarman, D. B. (1996). The Revised Conflit Tactics Scales (CTS2). Journal of Family Issues, 17, 283-316. 
Veltman, M. W. M., \& Browne, K. D. (2001). Three decades of child maltreatment research: Implications for the school years. Trauma, Violence, \& Abuse, 2, 215-239.

Werner, E. E. (1998). Protective factors and individual resilience. Em S. J. Meisels \& J. P. Shonkoff (Eds.), Handbook of early childhood intervention (pp. 97-116). Nova York: Cambridge University Press.

Williams, L. C. A., \& Aiello, A. L. R. (2004). Empoderamento de famílias: o que vem a ser e como medir. Em E. G. Mendes, M. A. Almeida \& L. C. A. Williams (Orgs.), Temas em educação especial: avanços recentes (pp. 197-202). São Carlos: EDUFSCar.
Wolfe, D. A., Crooks, C. V., Lee, V., McIntyre-Smith, A., \& Jaffe, P. G. (2003). The effects of children's exposure to domestic violence: A meta-analysis and critique. Clinical Child and Family Psychology Review, 6, 171-187.

Recebido em 24.07.07 Primeira decisão editorial em 17.06.08 Versão final em 17.07.08 Aceito em 27.11.08 